\title{
Effects of Aquatic Exercise in the Treatment of Obesity
}

\author{
Onur Oral ${ }^{1 *}$, PInar Tatlibal $^{2}$ and Evangelia Stavropoulou ${ }^{3}$ \\ ${ }^{1}$ Ege University, Faculty of Sports Sciences, Izmir, Turkey \\ ${ }^{2}$ Dokuz Eylul University, Faculty of Sports Sciences, Izmir, Turkey \\ ${ }^{3}$ Master of Research in Information and Communication, University of Lorraine, France
}

*Corresponding author: Onur Oral, Ege University Faculty of Sports Sciences, Department of Health Sciences and Sports, Izmir Turkey

\section{ARTICLE INFO}

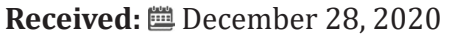

Published: 幽 January 06, 2021

Citation: Onur Oral, Pınar Tatlibal, Evangelia Stavropoulou. Effects of Aquatic Exercise in the Treatment of Obesity. Biomed J Sci \& Tech Res 33(1)-2021. BJSTR. MS.ID.005331.

Keywords: Water Exercise; Aquatic Exercise; Land Exercise; Obesity

\section{ABSTRACT}

Background: The aim of the study is to investigate the effects of aquatic exercises on human physiology and examine the possible beneficial results of this innovative therapy as a treatment for obese and overweight patients.

Materials and Methods: In the search for scientific literature related to this review the US National Library of Medicine (PubMed) used MEDLINE and Sport Discus data and the terms "aquatic exercise", "water exercise", "obesity", and "land exercise" were used. The relevant literature has also taken its source from the research of relevant articles from reference lists derived from data studies.

Results: Considering its density and resistance, aquatic exercise increases calorie loss with less fatigue. Benefits such as fat burn, increased flexibility, increased body strength, improved cardiovascular endurance are positive for obese individuals. Aquatic exercise is also known to improve body composition, respiratory system and circulatory system. Not only it is beneficial in a physiological sense, but this type of exercise also provides a more inviting environment for obese individuals.

Conclusion: The relationship between physical activity and obesity is unquestionable. There is strong evidence stating that aquatic exercise is more beneficial and efficient for treatment of obesity compared to land exercises. Aquatic exercise can be strongly recommended as a new way of therapy for obesity and offers promising results. Investigation of aquatic exercise's effects on obesity treatment should be further studied.

\section{Introduction}

Today, obesity is considered as a severe epidemic and a global health treat. Obesity is particularly quite common in developed countries. Ogden stated in the research that according to the data collected in 2010, 17\% of American youth suffers from obesity. Likewise, one third of the adults suffer from this disease as well [1]. In fact, one study claims that approximately half of USA citizens are expected to become obese or overweight in the next decade [2]. According to the data collected from European citizens, almost $13 \%$ of the adults reported being obese or overweight [3]. One reason why obesity is considered such serious health condition is that the disease leads to several other severe health problems such as cancer, diabetes, several cardiovascular problems etc. [4,5]. In order to reduce the risk of suffering from cardiovascular problems, an obese person should lose between 5-10 percent of their body mass [6]. Wessel et al. emphasized the significance of physical activity for reducing the risk of cardiovascular problems [7]. It is necessary to exercise at least half an hour a day in order to maintain proper weight [8].

\section{Obesity and Physical Activity}

Obesity is known to be the triggering factor for many disorders such as insulin resistance, dyslipidaemia, metabolic syndrome, coronary artery disease, hypertension etc. In fact, obesity severely affects the cardiovascular system [9-11]. In addition to causing many health problems, obese children are at high risk of being obese in the future as adults [12]. According to American College of Sports Medicine, obese teens are recommended to exercise at least 
three days a week in order to increase their physical strength. This study emphasizes the importance of physical activity and sports in the struggle against obesity [13-15].

\section{Water in comparison to Land Exercise}

Engaging in aquatic exercises is a new way of treatment for obesity. There are several reasons why water provides a more efficient environment for exercise for obese people [16,17]. Considering its density and resistance, working out in water provides calorie loss with less fatigue. Compared to land-based exercise, aquatic exercise is more efficient [18]. According to Nikolai et al., water aerobics which is a type of aquatic exercise is highly recommended as an alternate exercise to land exercise [19].

\section{Aquatic Exercises}

Aquatic exercise is rather a new way of therapy. Even though the programme dates back to 1980s, it only became prevalent in the past 20 years [20]. Aquatic exercise is performed for several reasons such as to lose weight, become fit and to more comfortably rehabilitate body after injuries [21,22]. In the past few years, many studies were concluded to investigate the effects of aquatic exercise on human physiology. According to many studies, aquatic exercise helps increase flexibility, burn fat, increase body strength and improve cardiovascular endurance [23-25]. Aquatic exercise is considered as a beneficial therapy that offer promising results $[26,27]$. Aquatic exercise influence human body in several ways. This type of exercise are assumed to have a significant effect on muscle strength and body endurance. Studies also indicate improvement in body composition, respiratory system and circulatory system. Circulatory system's wellness is particularly important for obese children [28]. Buoyant force in water is the key factor that makes aquatic exercise more efficient compared to ground exercises. In water, one is likely to exercise with more stability [29]. Other than its physiological benefits, aquatic exercise also provides psychological benefits to obese people. During aquatic exercise, one has the opportunity to cover their body and exercise without any concerns about their looks. This is likely to provide a more comfortable exercise environment for obese people [30].

\section{Physical and mental health enhancement/improvement of QOL}

\section{Weight loss/improved metabolism/pain-relief}

Characteristics of water

\begin{tabular}{|c|}
\hline Warmth \\
Buoyancy \\
Hydrostatic effect \\
Resistance \\
\hline
\end{tabular}

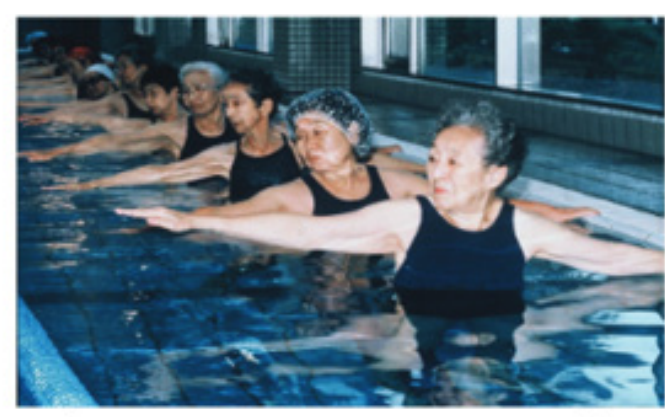

Exercise

Aerobic exercise
Strength training
Stretching

$\uparrow$

$\uparrow$

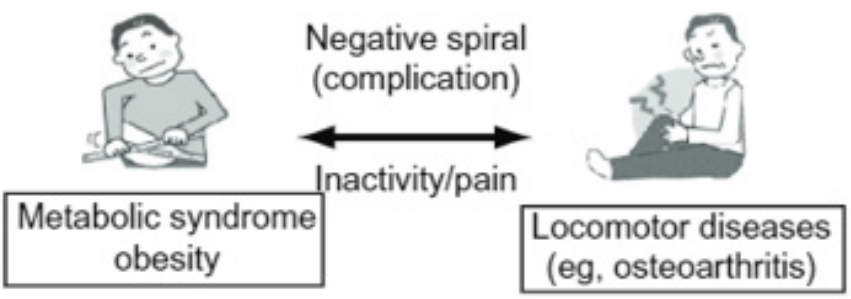

Figure 1: Results of aquatic exercise. (Reprinted from Honda, T, Kamioka H (2012) Curative and health enhancement effects of aquatic exercise: Evidence based on interventional studies).

\section{Equipment}

There are several factors that affect the level of efficiency of aquatic exercise. One study stated that the physiological results of aquatic exercise can be increased when the exercise performed along with buoyancy equipment [31]. Similarly, Pinto et al., recommended the use of floating equipment during aquatic exercise in order to receive better results in terms of cardiovascular and respiratory response [32]. 


\section{Water Depth}

Depth of water is considered as an important factor during aquatic-exercise. There are conflicting study results on the matter. Nuttamonwarakul et al., conducted a research on elder participants with diabetes. According to the results, the participants' body fat percentage, BMI and body mass levels were reduced when they participated in deep-water aquatic exercise [33]. Kantyka et al. conducted a study on middle aged women that were overweight. The women participated in aqua aerobics exercise for a period of 14 weeks. Their body mass was decreased yet their BMI showed no meaningful difference [34]. Another aqua aerobic study on postmenopausal women resulted in no difference in fa tor BMI [35].

\section{Discussion}

20 obese students at elementary school level were chosen to participate in the study of Lee and Oh. The study aimed to investigate how aquatic exercise affects human physiology. The mentioned study included a swimming and a control group. Both groups were given an 12 week exercise plan that required children to exercise 3 days a week. The body composition and fat percentage of the group that participated in aquatic exercise demonstrated considerable improvement. However, body strengths showed no variations [36]. Farahani et al., conducted a research on elderly and obese patients. The patients were chosen among people that suffered from orthopedic and bronchospasm disorders. Patients were asked to participate in a 10 week aqua aerobic programme. Improvements in the resting blood pressure was observed [37]. Likewise, another study by Barbosa et al., concluded that a 26 week aquatic exercise routine is likely to improve body composition in middle aged women. However, the researchers identified no positive changes in the BMIs of the women [38].

One study was conducted on university students for a period of 6 weeks to understand how aquatic exercise is linked to BMI. In the study, subjects were divided into two groups: on-land aerobic and water aerobics participants. The students exercised three times a week for a period of one hour. At the end of the study, BMI of both subject groups showed improvement. The researchers concluded that aquatic exercise can be a good alternative to on-land exercises for weight loss. In 2010, another study was conducted on 38 women who were not fit in order to assess the relationship between aquatic exercise and cardiovascular fitness. The ages of the participants differed from 30 to 62 . The subjects were divided into control and exercise groups. The women in exercise group were asked to participate in a 24 weeks aqua aerobic programme. The aerobic took place in deep water. According to the results, aerobic capacity of the women in exercise group increased considerably. In addition, their resting heart rates were estimated to be lower.

\section{Conclusion}

The relationship between physical activity and obesity is unquestionable. There is strong evidence stating that aquatic exercise is more beneficial and efficient for treatment of obesity compared to land exercises. Considering its density and resistance, aquatic exercise increases calorie loss with less fatigue. Benefits such as fat burn, increased flexibility, increased body strength, improved cardiovascular endurance are positive for obese individuals. Aquatic exercise is also known to improve body composition, respiratory system and circulatory system. Not only it is beneficial in a physiological sense, but this type of exercise also provides a more inviting environment for obese individuals. Aquatic exercise can be strongly recommended as a new way of therapy for obesity and offers promising results. Investigation of aquatic exercise's effects on obesity treatment should be further studied.

\section{References}

1. Ogden CL, Carroll MD, Kit BK, Flegal KM (2012) Prevalence of obesity in the United States, 2009-2010. NCHS Data Brief 82(2): 1-8.

2. Finkelstein EA, Khavjou OA, Thompson H, Trogdon JG, Pan L, et al. (2012) Obesity and severe obesity forecasts through 2030. Am J Prev Med 42(6): 563-570.

3. Gallus S, Lugo A, Murisic B, Bosetti C, Boffetta P (2015) Overweight and obesity in 16 European countries. Eur J Nutr 54(5): 679-689.

4. Poirier P, Giles TD, Bray GA, Hong Y, Stern JS, et al. (2005) Obesity and cardiovascular disease: pathophysiology, evaluation, and effect of weight loss. Arterioscler Thromb Vasc Biol 113(6):898-918.

5. Bielec G, Kwasna A, Gaworska P (2017) The influence of Aqua Power aerobics on body mass reduction in middle-aged, overweight women. Turk J Phys Med Rehabil 63(4): 293-298.

6. Wing RR, Lang W, Wadden TA, Safford M, Knowler WC, et al. (2011) Benefits of modest weight loss in improving cardiovascular risk factors in overweight and obese individuals with type 2 diabetes. Diabetes Care 34(7): 1481-1486.

7. Wessel TR, Arant CB, Olson MB, Johnson BD, Reis SE, et al. (2004) Relationship of physical fitness vs body mass index with coronary artery disease and cardiovascular events in women. JAMA 292(10): 1179-1187.

8. Chaput JP, Klingenberg L, Rosenkilde M, Gilbert JA, Tremblay A (2011) Physical activity plays an important role in body weight regulation. J Obes 2011: 360257.

9. Fang ZY, Yuda S, Anderson V, Short L, Case C (2003) Echocardiographic detection of early diabetic myocardial disease. J Am Coll Cardiol 41(4): 611-617.

10. Rader DJ (2007) Effect of insulin resistance, dyslipidemia, and intraabdominal adiposity on the development of cardiovascular disease and diabetes mellitus. Am J Med 120(3): S12-18.

11. Riera Fortuny C, Real JT, Chaves FJ, Morales Suárez Varela M, Morillas Ariño C (2005) The relation between obesity, abdominal fat deposit and the angiotensin converting enzyme gene I/D polymorphism and its association with coronary heart disease. Int J Obes 29(1): 78-84.

12. Eisenmann JC, Bartee RT, Wang MQ (2002) Physical activity, TV viewing and weight in U.S. youth (1999 youth risk behavior survey) Obes Res 10(5): 379-385.

13. Chae HW, Kwon YN, Rhie YJ, Kim HS, Kim YS (2011) Effects of a structured exercise program on insulin resistance, inflammatory markers and physical fitness in obese Korean children. J Pediatr Endocrinol Metab. 23(10): 1065-1072.

14. Jabbour G, Lemoine Morels S, Casazza GA, Hala Y, Moussa E (2011) Catecholamine response to exercise in obese, overweight, and lean adolescent boys. Med Sci Sports Exerc 43(3): 408-415.

15. Wong PC, Chia MY, Tsou IY, Wansaicheong GK, Tan B (2008) Effects of a 12 -week exercise training programme on aerobic fitness, body 
composition, blood lipids and C-reactive protein in adolescents with obesity. Ann Acad Med Singapore 37(4): 286-293.

16. Rippe JM, McInnis KJ, Melanson KJ (2001) Physician involvement in the management of obesity as a primary medical condition. Obes Res 9(Suppl 4): 302-311.

17. Noël PH, Pugh JA (2002) Management of overweight and obese adults. BMJ 325(7367): 757-761.

18. Folsom B (2008) Water weightlessness - the advantages of a water aerobics workout. Am Fitness 9(10): 66-67.

19. Nikolai AL, Novotny BA, Bohnen CL, Schleis KM, Dalleck LC (2009) Cardiovascular and metabolic responses to water aerobics exercise in middle-age and older adults. J Phys Act Health 6(3): 333-338.

20. Brody LT, Geigle PR (2009) Aquatic exercise for rehabilitation and training. 2009: Human Kinetics.

21. Delevatti R, Marson E, Kruel LF (2015) Effect of aquatic exercise training on lipids profile and glycaemia: a systematic review. Revista Andaluza de Medici-na del Deporte 8(4): 163-170.

22. Meredith Jones K (2011) Upright water-based exercise to improve cardiovascular and metabolic health: a qualitative review. Complementary therapies in medicine 19(2): 93-103.

23. De Mattos F (2016) Effects of aquatic exercise on muscle strength and functional performance of individuals with osteoarthritis: a systematic review. Re-vista Brasileira de Reumatologia 56(6): 530-542.

24. Kantyka J (2015) Effects of aqua aerobics on body composition, body mass, lipid profile, and blood count in middle-aged sedentary women. Human Movement 16(1): 9-14.

25. Kim SB, O sullivan DM (2013) Effects of aqua aerobic therapy exercise for older adults on muscular strength, agility and balance to prevent falling during gait. Journal of physical therapy science 25(8): 923-927.

26. Nikolai AL (2009) Cardiovascular and metabolic responses to water aerobics exercise in middle-aged and older adults. Journal of Physical Activity and Health 6(3): 333-338.

27. Madhan K (2016) Effect of Aqua Aerobic Exercises and Aerobic Exercises on Body Mass Index Pa-rameter Among College Men Students. International Journal of Innovative Knowledge Concepts $4(9)$.

ISSN: 2574-1241

DOI: 10.26717/BJSTR.2021.33.005331

Onur Oral. Biomed J Sci \& Tech Res

(C) This work is licensed under Creative

Commons Attribution 4.0 License

Submission Link: https://biomedres.us/submit-manuscript.php
28. Salvadori M, Sontrop JM, Garg AX, Truong J, Suri RS (2008) Elevated blood pressure in relation to overweight and obesity among children in a rural Canadian community. Pediatrics 122(4): 821-827.

29. Lee BA, Oh DJ (2014) The effects of aquatic exercise on body composition, physical fitness, and vascular compliance of obese elementary students. J ExercRehabil 10(3): 184-190.

30. Takeshima N (2002) Water-based exercise improves health-related aspects of fitness in older women. Medicine\& Science in Sports \& Exercise 34(3): 544-551.

31. Costa G, Afonso S, Bragada J, Reis VM, Barbosa TM (2008) Comparison of acute physiological adaptations between three variants of a basic headout water exercise. Rev Bras Cineantropom Desempenho Hum 10(4): 323-329.

32. Pinto SS, Cadore EL, Alberton CL, Silva EM, Kanitz AC, et al. (2011) Cardiorespiratory and neuromuscular responses during water aerobics exercise performed with and without equipment. Int J Sports Med 32(12): 916-923

33. Nuttamonwarakul A, Amatyakul S, Suksom D (2012) Twelve weeks of aqua-aerobic exercise improve physiological adaptation and glycemic control in elderly patients with type 2 diabetes. JEP Online 15(2): 64-70.

34. Sattar M, Esfarjani F, Nezakat Alhosseini M, Kordavani L (2012) Effect of aquatic resistance training on blood pressure and physical function of postmenopausal women. ARYA Atherosclerosis Journal 8: S178-S82.

35. Farahani AV (2010) The effects of a 10-week water aerobic exercise on the resting blood pressure in patients with essential hypertension. Asian journal of sports medicine 1(3): 159-167.

36. Barbosa TM (2011) Effects of a 26-week shallow water head-out aquatic exercise program on the anthropometrics, body composition and physiological response of healthy middle-aged women. in Aquatic Exercise Association 2011 International Aquatic Fit-ness Conference (IAFC). 2011. Aquatic Exercise As-sociation.

37. Piotrowska Calka E (2010) Effects of a 24-week deep water aerobics training program on cardiovascular fitness. Biol Sport 27(2): 95-98.

38. Honda T, Kamioka H (2012) Curative and health enhancement effects of aquatic exercise: Evidence based on interventional studies. Open access journal of sports medicine 3: 27-34.

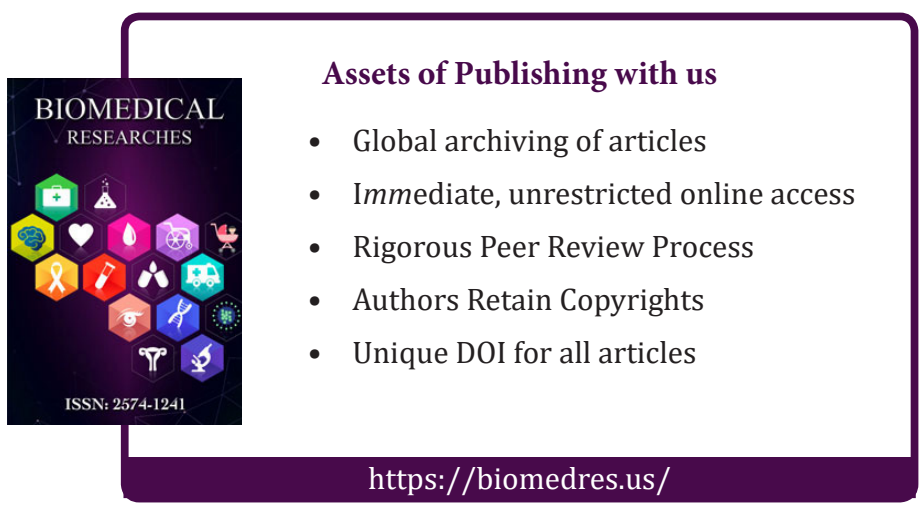

Copyright@ Onur Oral | Biomed J Sci \& Tech Res | BJSTR. MS.ID.005331. 